This item was submitted to Loughborough's Research Repository by the author.

Items in Figshare are protected by copyright, with all rights reserved, unless otherwise indicated.

\title{
Designing for safety during pregnancy through a system for automotive engineers
}

PLEASE CITE THE PUBLISHED VERSION

http://dx.doi.org/10.1533/ijcr.2004.0316

PUBLISHER

(c) Taylor \& Francis

VERSION

AM (Accepted Manuscript)

\section{PUBLISHER STATEMENT}

This work is made available according to the conditions of the Creative Commons Attribution-NonCommercialNoDerivatives 4.0 International (CC BY-NC-ND 4.0) licence. Full details of this licence are available at: https://creativecommons.org/licenses/by-nc-nd/4.0/

\section{LICENCE}

CC BY-NC-ND 4.0

\section{REPOSITORY RECORD}

Acar, B. Serpil, and Alix M. Weekes. 2019. "Designing for Safety During Pregnancy Through a System for Automotive Engineers”. figshare. https://hdl.handle.net/2134/23438. 


\title{
Designing for safety during pregnancy through a system for automotive engineers
}

\author{
BSAcar and A M Weekes \\ Department of Computer Science, Loughborough University, Loughborough, Leicestershire LE11 3TU, UK
}

\begin{abstract}
Pregnant women in the UK are legally required to wear seatbelts both as drivers and passengers. This paper considers fitting the seat belt correctly around the pregnant woman's altered body and explores the ways of providing data to automotive engineers. The paper presents the difficulties experienced during pregnancy resulting from women's altered shape and size. Accommodation of pregnant occupant anthropometry is key to improving seat belt use and positioning. An anthropometry website is presented with the aim of enhancing pregnant women's quality of life through an improved seat belt design. The website has been designed to suit the needs of automotive designers and engineers to encourage them to consider pregnant occupant protection.
\end{abstract}

Key words: Pregnant, occupant, safety, automotive design, website.

\section{INTRODUCTION}

Road traffic accidents are one of the leading causes of death, with 1.3 millions deaths worldwide in 2000 [1]. World Health Organisation predictions suggest road traffic accidents will rise from $9^{\text {th }}$ rank to $3^{\text {rd }}$ by the year $2020[2$, 3]. The largest cause of accidental death and disability in pregnancy is automobile collisions [4]. The Royal Society for the Prevention of Accidents safety publications report that seat belts and air bags prevent tens of thousands of deaths and serious injuries in the UK each year [5]. It is a legal requirement in the $\mathrm{UK}$ to wear seatbelts both as drivers and passengers $[6,7]$, and pregnant women are not exempt to this rule.

Crash test research [8] has shown the effectiveness of seat belts in reducing injury risk for pregnant women and their fetuses, and has focused on establishing the correct position for seat belts in pregnancy in order to reduce the risk of abdominal trauma. Current safety guidelines from the UK Department of Transport [7] and the National Highway Traffic Safety Administration in the USA [9] describe the correct position such that 'the lap strap should go across the hips, fitting comfortably under the bump, while the diagonal strap should be placed between the breasts and around the bump' [7]. However, Acar and Weekes [10] also reported that only $13 \%$ of pregnant women are actually wearing their seat belt in the correct position.

During pregnancy a woman's body undergoes significant changes in size and shape. These changes are not limited to the abdominal region, since the hips and breasts also increase in size. In this paper we focus on the ability of fitting the seat belt correctly around the pregnant woman's altered body and investigate the ways of providing data to automotive engineers.

The design process relies upon the use of anthropometric data to determine the portion of the user population that will be accommodated by the design. There is currently little data available for pregnant women, and the published data dimensions are often not relevant to automotive design. The study of the dimensional changes of the feet during pregnancy by Alvarez et al. [11] compares a sample of 17 pregnant women with 16 comparable nonpregnant women. This data is of little use for vehicle design since the sample size is extremely small, and only dimensions for foot length and width are given that are relevant to automotive design. The study by Yamana et al. [12] presents measurements of 520 pregnant women from the second to tenth month of pregnancy for a total of 44 dimensions. However very few measurements are applicable to automotive design since the paper was originally aimed at garment design. Pheasant [13] modified the data from Yamama et al. [12] for the abdominal depth and forward grip reach dimensions. Pheasant used a scaling method based on the assumption that pregnancy will cause British and Japanese women to change in a similar way, and that they are of similar proportions. The anthropometric data generated using the scaling method is therefore less reliable than real anthropometric measurements. Klinich et al. [14] present measurements of 22 pregnant women. 
Ten measurements pertinent to automotive design were recorded throughout the course of pregnancy. Therefore in general the availability of pregnant women's anthropometric data is limited, and little is relevant to vehicle design. It has also been difficult for designers to assess the suitability of their designs for the pregnant occupant, since there has been a lack of anthropometric data measured from pregnant women.

Recently, Acar and Weekes [15] presented analysis of a comprehensive set of 48 anthropometric measurements selected specifically for use in vehicle design as a contribution towards the solution of this problem. In this paper the Pregnant Women's Anthropometry Website is used to display this data in a user-friendly manner for automotive designers and engineers after a brief introduction of the measurement methods and analysis.

\section{METHOD}

Two data collection methods were used in this study, the first being a series of anthropometric measurements. 100 sets of measurements were recorded at the time of writing. The measurements recorded were adapted by the authors for pregnant women based on standard anthropometric postures [13]. Women were recruited in two locations in the United Kingdom: Loughborough University, and the Luton \& Dunstable Hospital National Health Service Trust. Volunteers wore light clothing and removed their shoes. The equipment used included an anthropometer, weight scales, a digital vernier caliper, a tape measure and a stadiometer. The abdominal, hip and chest region measurements (illustrated in Figure 1) were particularly useful in understanding how physical changes impact upon seat belt safety in pregnancy.

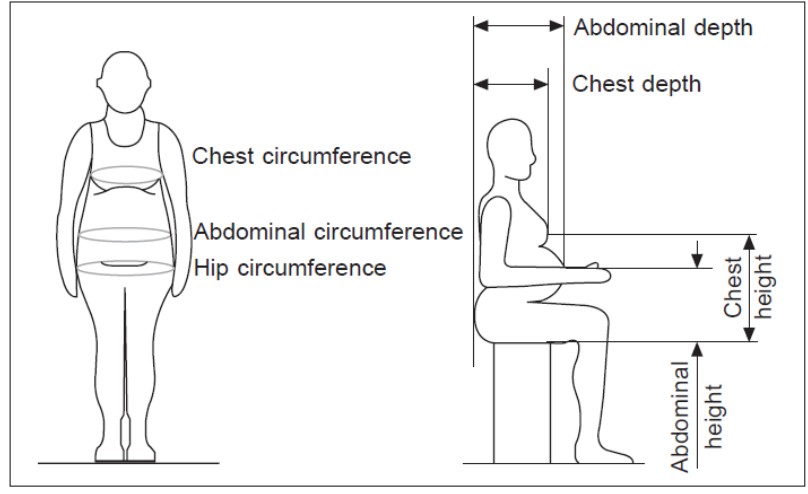

Figure 1 Anthropometric measurements with particular relevance to seat belt design.

The second data collection method was a 'Pregnancy and Driving Questionnaire' that was answered during an interview or by self-completion. 450 sets of questionnaire responses were processed at the time of writing. The questionnaire was also available for online completion in five languages (English, Spanish, Italian, Turkish and
French) at the Pregnant Driver website [16]. Responses have been received from around the world with the majority being from the UK $(63 \%)$, and the remainder from the rest of the world $(37 \%)$. The pregnant women were reminded repeatedly to compare their experiences when they were not pregnant against their experiences during pregnancy. The questions about seat belts included issues of seat belt use and positioning, and attitudes and information received about seat belts in pregnancy.

Table 1 provides a summary of the gestation levels of the pregnant women recruited to this study. The majority of these women normally occupy the driver's seat. Occasionally they use the front or rear passenger seats, and in a few cases the normal occupant position is unknown.

\section{SEAT BELTS}

\section{Fitting and positioning}

The DFT and NHTSA advise pregnant women that the correct seat belt position is as follows: 'the lap strap should go across the hips, fitting comfortably under the bump, while the diagonal strap should be placed between the breasts and around the bump' [7]. 95\% of the pregnant volunteers who responded to the questionnaire reported that they were wearing their seat belt during pregnancy. However only $13 \%$ of pregnant women using their seat belt actually had their seat belt correctly positioned according to the guidelines.

It is not surprising that the pregnant women report problems with seat belt positioning when they are physically so altered. The anthropometric measurements recorded show that the pregnant woman's body undergoes dramatic transformation during pregnancy [15]. For example the biggest changes occur in abdominal circumference where pregnant women's abdominal circumference may be up

to $1410 \mathrm{~mm}$, which is $452.8 \mathrm{~mm}$ larger than the $95^{\text {th }}$ percentile value for non-pregnant UK females. The changes are not limited to the abdominal region, but occur throughout the body. The breasts and hips also enlarge notably due to pregnancy, as well as the abdominal protrusion.

For pregnant women measured in the third trimester the lower bound of the $95 \%$ confidence interval of the mean for the standing abdominal circumference is greater than the $95^{\text {th }}$ percentile value for UK non-pregnant females given in [17]. The lower bound of the confidence interval is also larger than the male $95^{\text {th }}$ percentile [17] so even using data for large males might be inadequate. These confidence intervals lie completely outside the $5^{\text {th }}$ to $95^{\text {th }}$ percentile range of currently available data. This highlights the importance of considering the pregnant occupant as a separate user group in order to accommodate their particular physical sizes.

However, the most important change for seat belt fitting is the increment in hip circumference because the lap belt is supposed to pass across the hips. Changes to hip circumference in pregnancy illustrate the importance of considering pregnant women's full anthropometry. 
Table 1. Pregnancy and driving details of the sample of pregnant women

\begin{tabular}{|c|c|c|c|c|c|c|}
\hline & \multirow{2}{*}{$\begin{array}{l}\text { No. } \\
\text { volunteers } \\
\text { (women) }\end{array}$} & \multicolumn{2}{|c|}{ Week of pregnancy } & \multicolumn{3}{|c|}{ Women's usual driving activities } \\
\hline & & $\begin{array}{l}\text { Mean } \\
\text { (weeks) }\end{array}$ & $\begin{array}{l}\text { Std. dev. } \\
\text { (weeks) }\end{array}$ & $\begin{array}{l}\text { Drivers } \\
\text { (women) }\end{array}$ & $\begin{array}{l}\text { Non-driver } \\
\text { (women) }\end{array}$ & $\begin{array}{l}\text { Unknown } \\
\text { (women) }\end{array}$ \\
\hline \multicolumn{7}{|c|}{ Anthropometric measurements } \\
\hline Second trimester ${ }^{b}$ & 35 & 21.6 & 4.5 & 34 & 0 & 1 \\
\hline Third trimester ${ }^{\mathrm{c}}$ & 65 & 35.5 & 2.8 & 52 & 4 & 9 \\
\hline \multicolumn{7}{|c|}{ Pregnancy and driving questionnaire } \\
\hline First trimester $^{\mathrm{a}}$ & 34 & 8.5 & 2.3 & 32 & 2 & 0 \\
\hline Second trimester ${ }^{\mathrm{b}}$ & 159 & 21.6 & 4.4 & 156 & 2 & 1 \\
\hline Third trimester ${ }^{\mathrm{c}}$ & 257 & 35.2 & 3.3 & 243 & 5 & 9 \\
\hline
\end{tabular}

${ }^{\mathrm{a}}$ The first trimester lasts until the $12^{\text {th }}$ week of pregnancy.

${ }^{\mathrm{b}}$ The second trimester is from the $13^{\text {th }}$ to the $28^{\text {th }}$ week of pregnancy.

'The third trimester is from the $29^{\text {th }}$ week of pregnancy until the birth $(40+$ weeks).

Figure 2 shows how much larger pregnant women's hip circumference is in the third trimester, when compared to non-pregnant UK female or male data currently available in [17]. The mean standing hip circumference is 1155.1 $\mathrm{mm}$ for the women in the third trimester, which is 118.1 $\mathrm{mm}$ larger than for non-pregnant women's anthropometric data given in [17]. Similarly it is $108.6 \mathrm{~mm}$ larger than the mean male standing hip circumference. This suggests that a woman nearing the end of pregnancy would need an approximately $12 \mathrm{~cm}$ longer seat belt.

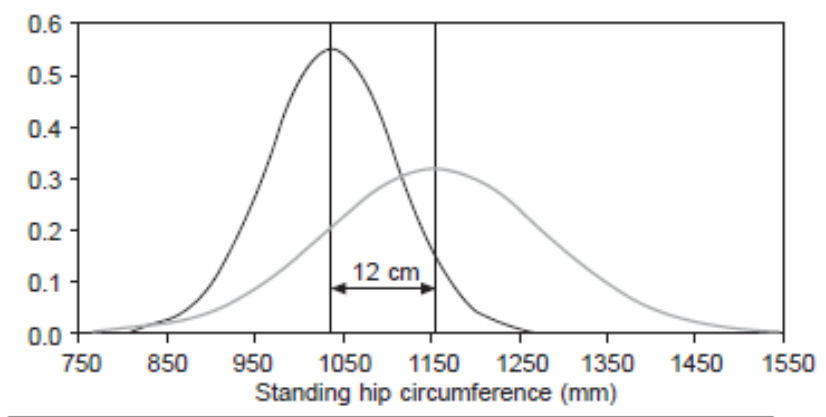

Pregnant women in third trimester (measurements from this study) - Non-pregnant UK females [DTI, Adultdata, London, 1998]

Figure 2 Pregnant occupants have approximately 12 $\mathrm{cm}$ larger standing hip circumference during the third trimester.

Even if seat belt designs were based on the $95^{\text {th }}$ percentile male value for hip circumference of $1168.2 \mathrm{~mm}$, they would still exclude many pregnant women. This is because the $95^{\text {th }}$ percentile for male standing hip circumference in [17] is equivalent to only the $55^{\text {th }}$ percentile value for measurements recorded from pregnant women in the third trimester. Hence $45 \%$ of pregnant women would be excluded by a design based on currently available data, even if the male $95^{\text {th }}$ percentile is used as shown in Figure 3.

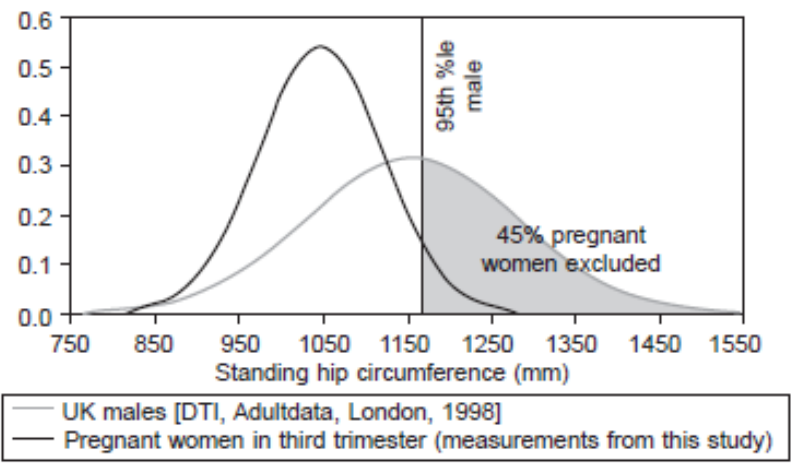

Figure 3 Pregnant occupants have a larger standing hip circumference so even designs using UK male $95^{\text {th }}$ percentile data could exclude $45 \%$ of pregnant women in the third trimester.

Use of pregnant women's anthropometric data during the design stages might help to reduce seat belt discomfort problems, which is particularly important since some pregnant women are discouraged from using the seat belt due to discomfort [10]. It is important for the automotive industry to accommodate the pregnant women's anthropometric needs throughout the entire course of pregnancy, because the seat belt positioning may change as body shape alters. For example, the tendency for the lap portion of the seat belt to ride up onto the abdomen is highest in the second trimester, whereas in the third trimester the enlarged abdomen helps to hold down the lap belt more securely across the hips [10]. The authors not only recommend that the anthropometric data be used to check seat belt fit for the pregnant occupant, but also at least static user testing with pregnant volunteers. This will help the designers and engineers gain further insight into the notable physical changes occurring throughout the body during pregnancy, and how these changes affect seat belt positioning. 


\section{ANTHROPOMETRY WEBSITE AND INTERFACE}

A website presenting the anthropometric measurements of pregnant women was produced, and is illustrated in Figure 4. The aim of the site is providing this anthropometric data to automotive designers for assessment of designs for accommodation of pregnant occupants. This will subsequently help to incorporate the altered physical needs of pregnant women into vehicle designs. The web format was selected so all parts of the automotive industry could access the data regardless of particular software systems used for design. This is the first anthropometry website to be produced and is especially unique in providing anthropometric measurements of pregnant women specifically selected for use in vehicle design. The site is aimed at automotive designers and engineers, but the measurements may also be useful to other areas of design. The site includes a page describing the project aims and objectives so automotive designers can understand the research project and background. The target user group is automotive designers and engineers, so the entire site has been designed to suit their human-computer interaction and usability needs.
A contact page is provided so automotive designers can request modifications to the site if necessary. The users are also invited to provide feedback and comments about the pregnant women's anthropometry website, to ensure it meets their needs.

The website uses engineering terminology so the automotive designers and engineers feel familiar with the terms. The anthropometric measurements were selected from the standard measurements depicted in the literature $[13,17]$, which the automotive designers are also familiar with. In a few cases the authors either added new measurements or adapted the standard measurement in order to better define the pregnant form. A full description of every measurement (including the new and adapted ones) is given so that automotive designers and engineers can be aware of the exact detail of the data recorded. Any gynecological terms are defined, for example on the search page the stage of pregnancy is given in trimesters, but the week of pregnancy is displayed alongside in parentheses for clarification.

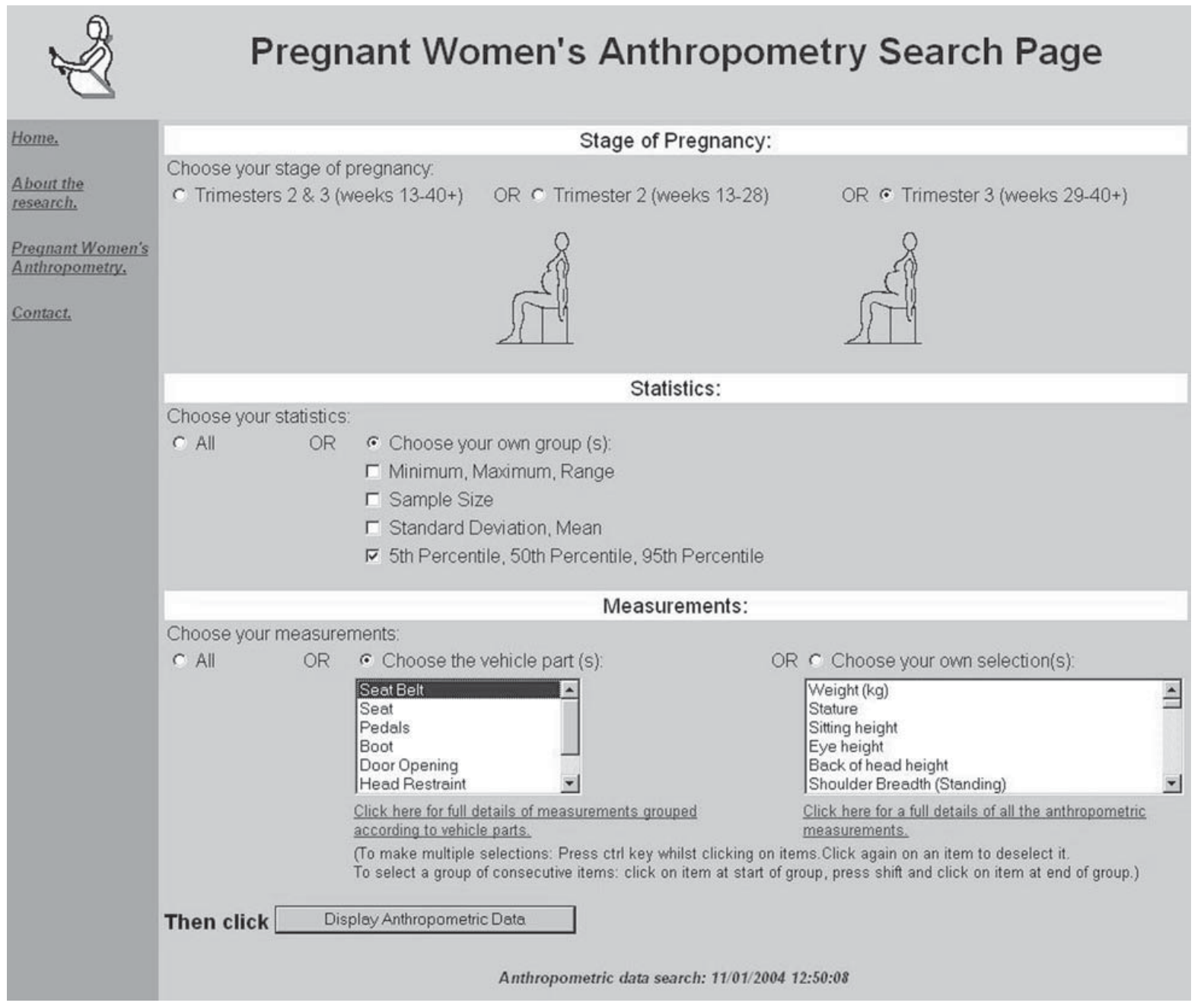

Figure 4 A screenshot of the Pregnant Women's Anthropometry Website data search page. 
The anthropometric data is stored in a MySQL database, which is queried using PHP code. The engineers and designers use a simple HTML search page to interface with the PHP code and control exactly which data is retrieved from the database. The search page (Figure 4) has simple radio buttons, checkboxes, and lists to aid the users' choices. The search process is broken into three steps, each of which is clearly labelled with a heading and instruction of how to proceed. The three steps of the search are:

1. Choosing the stage of pregnancy

2. Choosing the statistics about the measurements

3. Choosing the anthropometric measurements

The first step for the automotive designer is choosing the stage of pregnancy. The user can choose the stage of pregnancy by selecting a radio button for the trimester(s) of interest. Images of a pregnant woman with a small bump for Trimester 2, and a much larger bump for trimester 3 are used to visually represent the stages of pregnancy as an aid for understanding. Anthropometric data is not provided for pregnant women in the first trimester.

The automotive designers are given the choice to display data for women measured in the:

- second trimester

- third trimester

- or both second and third trimesters together

The third trimester is the period of greatest abdominal size, however the second trimester is also a time of great change and has particular problems associated with it. For example, the problem of the lap belt riding up onto the abdomen is greatest in the second trimester. Providing data for the women in the second and third trimesters separately should encourage automotive designers to accommodate women's changing physical needs throughout pregnancy.

The second step the user makes is choosing which statistics to display about the anthropometric data. These selections have also been aimed at the automotive industry. Automotive designers can either choose to display all the statistics, or make their own personalised selection by ticking the checkboxes in the list. The choice of statistics includes the:

- minimum, maximum and range

- sample size

- mean and standard deviation

- $5^{\text {th }}, 50^{\text {th }}$, and $95^{\text {th }}$ percentiles

The percentile calculations are provided because the $5^{\text {th }}$, $50^{\text {th }}$, and $95^{\text {th }}$ percentiles are the statistics used in typical design practice for accommodating $90 \%$ of the population. The minimum and maximum data are given to provide information about extreme cases occurring in pregnancy, and so automotive designers could aim to accommodate a larger portion of the pregnant population. This could also benefit obese people. The sample size data provides understanding of how many women's measurements are included in the sample, which is 100 at the time of writing. The third and final step for automotive designers is choosing which anthropometric measurements to display.

The user may choose the measurements by using one of three methods, including:

- choose the entire list of 48 measurements

- make a personalised selection of measurements from the list

- choose by the vehicle part they are designing

If the user is making their own personalised selection of measurements, they simply click on the measurements in the list. There is a link underneath the list to a page providing the full details of every measurement, and this page opens as a separate browser window to enable easy referencing between measurement details and the search page. This allows the automotive designers to know the exact details of the measurements so they can make a fully informed choice. The details provided in the reference page about each individual measurement include:

- a diagram providing a visual representation as an aid to understanding

- the measurement name

- the body landmarks between which themeasurement is recorded

- the posture (either standing or seated)

- the equipment used

The automotive designers also have the option to choose measurements to display according to the part of the vehicle they are designing, for example the seat belt. In this case all measurements of any body part making contact with that particular vehicle part are presented. For the seat belt option, the measurements of the abdomen, hips, breasts, and shoulders are displayed. The weight and stature of pregnant women are also given providing an indication of overall size. Any dimensions useful for defining locations of vehicle parts in relation to the occupant are also given. For reference purposes there is a separate page defining which anthropometric measurements are associated with different vehicle parts, shown in Figure 5. A link to this reference page is given underneath the vehicle parts list so the user can easily get additional information about this feature. The reference page opens a new browser window so the user can make references whilst making choices on the search page. The ability to choose the measurements according the vehicle part is advantageous to the designers and engineers, and it saves time.

For both the vehicle parts list and the measurements list the user can select just one individual list item (either a measurement or a vehicle part). Alternatively they can make multiple selections by holding the control key whilst clicking on the items. The user can also select a group of consecutive items by clicking the first item in the group then holding the shift key and clicking the item at the end of the group. The ability to make multiple selections in these lists helps automotive designers to make their own personalised selections to suit their particular aspect of vehicle design. 


\begin{tabular}{|c|c|c|c|c|c|c|c|c|c|c|}
\hline \multirow{2}{*}{$\begin{array}{l}\text { Home } \\
\text { About the } \\
\text { research. } \\
\text { Pregnant } \\
\text { Women's } \\
\text { Anthropometry } \\
\text { Contact }\end{array}$} & \multicolumn{10}{|c|}{$\begin{array}{l}\text { This chart shows which measurements are displayed according to different parts of the car. For } \\
\text { example if you select 'seat belt' on the search page, only the measurement data relevant to seat belts } \\
\text { will be displayed in the results table. } \\
\text { Jump to the bottom of the table. }\end{array}$} \\
\hline & No. & Name & $\begin{array}{l}\text { Seat } \\
\text { belt }\end{array}$ & Seat & Pedals & Boot & $\begin{array}{l}\text { Door } \\
\text { opening }\end{array}$ & $\begin{array}{l}\text { Head } \\
\text { restraint }\end{array}$ & $\begin{array}{l}\text { Steering } \\
\text { wheel \& } \\
\text { clearance }\end{array}$ & $\begin{array}{l}\text { Dashboard } \\
\text { controls }\end{array}$ \\
\hline & 1 & Weight (kg) & $\bullet$ & $\bullet$ & $\bullet$ & $\bullet$ & $\bullet$ & $\bullet$ & $\bullet$ & $\bullet$ \\
\hline & 2 & Stature & $\bullet$ & $\bullet$ & $\bullet$ & $\bullet$ & $\bullet$ & $\bullet$ & $\bullet$ & $\bullet$ \\
\hline & 3 & Sitting height & & $\bullet$ & & & & $\bullet$ & & \\
\hline & 4 & Eye height & & $\bullet$ & & & & $\bullet$ & & $\bullet$ \\
\hline & 5 & $\begin{array}{l}\text { Back of head } \\
\text { height }\end{array}$ & & $\bullet$ & & & & $\bullet$ & & \\
\hline & 6 & $\begin{array}{l}\text { Shoulder breadth } \\
\text { (Standing) }\end{array}$ & & & & $\bullet$ & $\bullet$ & & & \\
\hline & 7 & $\begin{array}{l}\text { Shoulder breadth } \\
\text { (sitting) }\end{array}$ & & $\bullet$ & & & $\bullet$ & & & $\bullet$ \\
\hline
\end{tabular}

Figure 5 A screenshot of the Vehicle Parts page displaying which measurements are associated with different parts of the vehicle.

Once the automotive designer has completed the three steps of the search and made their choices of the stage of pregnancy, statistics, and measurements to display, they simply display the anthropometric data by clicking on the "Display Anthropometric Data" button.

The data page displays a table of anthropometric data, according to the selections made in the search page. Each measurement has one row of the table, and is clearly labelled in the left-hand column with the measurement name. The statistics selected are given a column each and are also labelled clearly in the top row of the table. The table resizes according to the number of measurements and statistics that were selected. Above the table is a heading to identify the stage of pregnancy so the user is reminded of their selection. For example if the user selected 'trimester 3' to display measurements from women in the third trimester of pregnancy, the heading clearly states "Trimester 3 (weeks 2940+)".

Also above the table a button to return to the search page can be used, as well as the back button in the browser. When the user returns to the search page the choices from their previous search are displayed. This has two benefits, first that the user does not have to remember the previous choices, and secondly that the user is able to make modifications based on the previous search.

The user can click on the measurement name in the data table, which is a hypertext link, to display the full details about that particular measurement. The details including a diagram are displayed in a pop-up window so that both the measurement details and the anthropometric data statistics can be viewed simultaneously. If the user wishes to display details for another measurement, these details are displayed in the same pop-up window so there is no risk that multiple pop-up windows would confuse the user.
The website has an error checking facility to ensure the user completes all the required sections of the search page. If the user leaves any or all of the sections (stage of pregnancy, statistics, measurements) blank, an error message will be displayed. The error message informs the user of the incomplete section, so the user knows exactly how to correct the error and successfully display the anthropometric data. An additional feature is that the user can click a statistics checkbox or measurement item to make a selection without necessarily having to click the associated radio button because the radio button will be automatically selected for them. For example if the automotive designer wishes to select the sample size check box they do not have to select the 'choose your own group(s)' radio button because it will be automatically selected. This not only prevents errors on the search page, but also helps to save automotive designers' time.

\section{CONCLUSIONS}

This study reveals that only $13 \%$ of pregnant women actually had the seat belt correctly positioned according to current safety guidelines. The correct position for the seat belt is 'the lap strap should go across the hips, fitting comfortably under the bump, while the diagonal strap should be placed between the breasts and around the bump' [7]. Since many seat belt fit and positioning problems experienced by pregnant women are caused by alterations in size and shape, accommodating women's altered anthropometry will be of greatest benefit. Pregnant women's physical size and shape changes require that the pregnant occupant should be considered as a separate user group in order to meet their specific needs. The pregnant occupant anthropometry could be used during the design stages to check the fit and positioning of the seat belt. 
Designers are also recommended to consider both the second and third trimesters of pregnancy because the fit of the seat belt is constantly changing as pregnancy progresses.

A pregnant women's anthropometry website was generated to present the anthropometric data gathered in this research. This website displays measurements specifically selected for use in vehicle design, and is the first such resource of its kind. The site was designed for use by engineers and designers to suit their needs, in order to encourage consideration of the pregnant occupant during the design stages. The website has many features to aid the user, in particular the ability to select the anthropometric measurements according to the vehicle part being designed. Incorporating the needs of pregnant women and modifying seat belt design accordingly can help to improve seat belt fit and use for the pregnant population. The anthropometry website is provided for automotive designers and engineers with the aim of enhancing pregnant occupant protection through an improved seat belt design.

\section{ACKNOWLEDGEMENTS}

The "Automotive Design: Incorporating the Needs of Pregnant Women" project is funded by the EPSRC (Engineering and Physical Sciences Research Council, UK) research grant GR/R13081 of the Innovative Manufacturing and Research Centre. The authors wish to express their thanks to sponsors, collaborating car manufacturers, consultant Obstetrician and Gynaecologist M. Griffiths, and all pregnant women who have participated in this research.

\section{REFERENCES}

1. Peden, M, McGee, K and KRUG, E. 'Injury: A leading cause of the global burden of disease 2000', World Health Organization, Geneva, 2002.

2. Murray, C and Lopez, A. (Eds) 'The global burden of disease: a comprehensive assessment of mortality and disability from diseases, injuries, and risk factors in 1990 and projected to 2020', Harvard School of Public Health, Boston 1996.

3. World Health Organization (WHO), 'World Report on Road Traffic Injury Prevention', World Health Organization, Geneva, 2004.

4. Pearlman, M D. 'Motor vehicle crashes, pregnancy loss and preterm labor', Int J Gynaecol Obstet, 199757 (127- 132 .
5. Royal Society for the Prevention of Accidents (RoSPA), 'Seatbelts and Child Restraints Factsheet ', Royal Society for the Prevention of Accidents, Birmingham, 2003.

6. Driving Standards Agency UK (DSA), The Highway Code, The Stationery Office Books, London, 1999.

7. Department for Transport UK (DFT), 'Seat belts and child restraints', Department for Transport UK, London, 2003, T/INF/251.

8. Crosby, W M, King, A I and Stout, L C. 'Fetal survival following impact: improvement with shoulder harness restraint', Am J Obstet Gynecol 1972112 (8) 1101-1106.

9. National Highway Traffic Safety Administration (NHTSA), 'Should pregnant women wear seatbelts', National Highway Traffic Safety Administration (NHTSA), Washington DC, USA, 2002, DOT HS 809506.

10. Acar, B S and Weekes, A M. 'Pregnant driver behaviour and safety', First International Conference on Driver Behaviour and Training, Stratford-upon-Avon, UK, Ashgate, 2003.

11. Alvarez, R, Stokes, I A F, Aspirnio, D E, Trevino, $\mathrm{S}$ and Braun, T. 'Dimensional changes of the feet in pregnancy', J Bone Joint Surg [Am], 1988 70A (2) 271-274.

12. Yamana, N, Okabe, $\mathrm{K}$, Nakano, $\mathrm{C}$, Zenitani, $\mathrm{Y}$ and SAIT A, T. 'The body form of pregnant women in monthly transitions', Jpn J Ergon, 198420 (3) 171178.

13. Pheasant, S. Bodyspace: Anthropometry, Ergonomics, and Design, Taylor \& Francis, London, 1986.

14. Kuinich, K D, Schneider, L W, Eby, B and Rupp, J D. 'Seated Anthropometry During Pregnancy', University of Michigan Transportation Research Institute, Michigan, 1999, UMTRI-99-16.

15. Acar, B S and Weekes, A M. 'Design Guidelines for Pregnant Occupant Safety', Journal of Automotive Engineering, (in press).

16. The Pregnant Driver Website: http://pregnantdriver.lboro.ac.uk.

17. Department of Trade and Industry (DTI), Adultdata: The handbook of adult anthropometric and strength measurements - data for design safety, Department of Trade and Industry, London, UK, 1988 